NASA Technical Memorandum 102391

\title{
Thermal/Structural Analyses of Several Hydrogen-Cooled Leading-Edge Concepts for Hypersonic Flight Vehicles
}

Herbert J. Gladden, Matthew E. Melis, and Theodore T. Mockler National Aeronautics and Space Administration Lewis Research Center Cleveland, Ohio

and

Mike Tong

Sverdrup Technology, Inc.

NASA Lewis Research Center Group Cleveland, Ohio

Prepared for the 28th Aerospace Sciences Meeting sponsored by the American Institute of Aeronautics and Astronautics Reno, Nevada, January 8-11, 1990

\section{NRSA}




\title{
Thermal/Structural Analyses of Several Hydrogen-Cooled Leading-Edge Concepts for Hypersonic Flight Vehicles
}

\author{
Herbert J. Gladden*, Matthew E. Melis, and Theodore T. Mockler \\ National Aeronautics and Space Administration \\ Lewis Research Center \\ Cleveland, Ohio \\ and \\ Mike Tong \\ Sverdrup Technology, Inc. \\ NASA Lewis Research Center Group \\ Cleveland, Ohio
}

\section{Summary}

The aerodynamic heating at high flight Mach numbers, when shock interference heating is included, can be extremely high and can exceed the capability of most conventional metallic and potential ceramic materials available. Numerical analyses of the heat transfer and thermal stresses are performed on three actively cooled leading-edge geometries (models) made of three different materials to address the issue of survivability in a hostile environment. These analyses show a mixture of results from one configuration to the next. Results for each configuration are presented and discussed. Combinations of enhanced internal film coefficients and high material thermal conductivity of copper and tungsten are predicted to maintain the maximum wall temperature for each concept within acceptable operating limits. The exception is the TD nickel material which is predicted to melt for most cases. The wide range of internal impingement film coefficients (based on correlations) for these conditions can lead to a significant uncertainty in expected leading-edge wall temperatures. The equivalent plastic strain, which results from the high thermal gradients, inherent in each configuration indicates a need for further cyclic analysis to determine component life.

\section{Nomenclature}

$b \quad$ equivalent slot height

$c_{p} \quad$ specific heat

$G \quad$ mass velocity

$h$ heat-transfer coefficient

$K(\theta)$ coefficient in eq. (6)

$k$ thermal conductivity

$L^{*} \quad$ entrance effects parameter

$l$ passage length from entrance

$\mathrm{Nu} \quad$ Nusselt number, $h(2 b / k)$

Pr Prandtl number, $c_{p}(\mu / k)$

Re Reynolds number, $G(2 b / \mu)$

St Stanton number

$S t_{\max }$ stagnation point Stanton number

$T_{b} \quad$ fluid temperature

$T_{r} \quad$ temperature ratio, $T_{w} / T_{b}$

$T_{w} \quad$ wall temperature

$T_{r}^{n} \quad$ coolant to wall temperature ratio

- Member AIAA 
$\mu \quad$ viscosity

\section{Introduction}

The high heat flux encountered by the leading edge of hypersonic aircraft in flight imposes severe demands on the materials and structures used for these applications. The aerodynamic heating at high flight Mach numbers (Holden et al. 1988), when the bow-shock wave impingement on the engine cowl leading edge is included, can be extremely high and can exceed the capability of most metallic and potential ceramic materials available. Not only must the high heating rates be tolerated, but the distortions caused by thermal warping of the structure must be kept to a minimum to achieve satisfactory inlet aerodynamic performance and component life. Consequently, there is a need for actively cooled leading-edge structures, fabricated from lightweight high-temperature materials, which incorporate efficient cooling concepts that will permit the structure to survive the hostile environment.

The general approach to this problem is to employ a thinwalled, actively cooled structure using materials with adequate modulus and thermal conductivity to minimize the thermal effects which can ultimately lead to elastic-plastic deformation of the structure. The actively cooled leading-edge concepts considered in this study are an impingement/pin fin-cooled concept, an impingement/convection-cooled design, and a convection-cooled design. These cooling schemes are coupled with a hydrogen cooling system to provide the large heat sink capability required to remove the incident heat flux.

This paper presents the results of a numerical study of the aforementioned actively cooled leading-edge concepts. These analyses incorporate the interactions between the fluid mechanics of the cooling schemes with the elastic-plastic behavior of the structures subject to the high thermal gradients. The materials assumed for each concept analyzed are Narloy- $Z$ (a copper alloy), TD nickel, and pure tungsten. Cryogenic gaseous hydrogen is assumed to be the coolant. Since there is limited information available for impingement cooling with hydrogen at high Reynolds numbers, two different correlations are considered in the analyses to demonstrate the potential extremes. Two- and/or three-dimensional steady-state nonlinear thermal/structural analyses are performed on these concepts with SINDA, a finite-difference code, and MARC, a finiteelement code. These analyses are made for an assumed shock interference heating boundary condition.

The results are presented as typical temperature distributions in the various concepts and the three material types. The associated equivalent plastic strain characteristics are also discussed.

\section{Numerical Models}

PATRAN II, a finite-element pre- and post-processor, is used to create all three models for this study. This approach allows the temperatures and thermal gradients to be determined accurately by the thermal analyzer and then to be transmitted by a one-to-one correspondence to the structural analyzer. Each of these models is described in more detail in subsequent sections. Translation software was used to convert the PATRAN model to data useful to MARC, a finite-element structural analysis code, and SINDA, a finite-difference heattransfer analysis code.

\section{Impingement/Pin Fin-Cooled Model}

Configuration 1, originally designed under the auspices of the NASA Langley Research Center (Killackey et al. 1980) as a strut support in a hypersonic flow field (fig. 1), consists of a series of channels in the center of the strut which bring coolant to the leading edge. Jets from the these channels impinge the semicylinder of the leading edge and then split and flow rearward through the pin fins incorporated in the upper and lower surfaces. The ratio of the target distance to the equivalent slot height for the impingement-cooled leading edge is 3.8. The leading-edge diameter is 0.112 inch and the wall thickness is 0.025 inch. The pin fins are a triangular array of 0.040 -inch-diameter pins on a center-to-center spacing of 0.065 inch (staggered row configuration). The pin height is 0.015 inch.

A three-dimensional numerical impingement model is constructed as shown in figure 2 . Using symmetry along both the horizontal centerline of the structure and the coolant channel helps to reduce the number of nodes and elements required. Because of the expected low thermal gradients away from the leading-edge region, a smaller segment of the model is used for subsequent MARC analyses. Bar elements are used to connect the outer skin with the structure to represent the pin fins but are not shown in this figure.

\section{Impingement/Convection-Cooled Model}

The impingement/convection model (configuration 2) is similar to the previously discussed model. However, instead of pin fins in the outer coolant channels, these passages are continuous rectangular channels. Because of the simple geometry of this structure, only one channel of the structure is modeled as a two-dimensional case with plane strain elements.

The ratio of the target distance to the slot height is 4.0 for the leading-edge impingement geometry of this model. The leading-edge diameter is 0.25 inch and the wall thickness is 0.007 inch. 
As before, only the local leading-edge region is modeled as seen in figure 3 . Note the higher density of elements in the leading-edge region to capture the larger thermal gradients in this area.

\section{Convection-Cooled Model}

The coolant path for the convection-cooled model (configuration 3) is a continuous flow loop past the leading edge in the axial direction. Heat transfer in the leading edge is enhanced by the curvature effect on the fluid as it reverses direction around the leading edge. The leading-edge diameter for this model is 0.375 inch. The wall thickness is 0.020 inch. As with the pin fin model, only one channel of the structure is modeled in three dimensions using primarily eight noded hexagonal elements and some six noded wedges. A higher density of elements is maintained in the leading-edge region to model the high thermal gradients (fig. 4).

\section{Computational Procedure}

Each of these models is created with both SINDA (finitedifference code) and MARC (finite-element code) analyses in mind. After a mesh is completed, PATRAN model data are written as ASCII data into the neutral file. This neutral file can easily be accessed by a wide variety of interface programs in order to translate PATRAN model data to any analysis program input data. PATSIN and PATMAR are programs used to interface PATRAN model data to SINDA and MARC, respectively. PATSIN utilizes a somewhat unique translation method because it must take data intended for finite-element analysis and convert them into a nodal network compatible with the finite-difference method of SINDA.

\section{SINDA Heat-Transfer Analysis}

A thermal analysis of each model is made using the Network Analysis Associates thermal analyzer (SINDA) with fluid/ thermal analyses added as subroutines. The node temperature results are then transferred to MARC as fixed temperature load data via the SINDA to NASTRAN Interface Program (SNIP) (Winegar 1987). This program is modified to generate NASTRAN or MARC grid/temperatures for two- or threedimensional models.

The SINDA models are made using diffusion nodes for the structure, arithmetic nodes on the surface of the structure, and boundary nodes representing the coolant in the internal passages. The fluid/thermal analyses subroutine uses the coolant inlet conditions and the coolant passage wall temperatures obtained from SINDA to calculate the local coolant film coefficient and fluid temperature. This subroutine assumes a one-dimensional, mixed, compressible, steady flow of an ideal gas. The fluid temperatures are then used to update the SINDA boundary node temperatures, and the local film coefficients are used to update the two-way conductors between the SINDA nodes on the coolant passage surfaces and the boundary nodes representing the fluid.

The coolant for these studies is assumed to be normal gaseous hydrogen at about $100 \mathrm{R}$ and 2000 to 4000 psia. The properties of the fluid are based on values compiled by McCarty (1975). The temperature-dependent material thermal conductivities are taken from the literature (Battelle Columbus Laboratories 1967 and Touloukian 1970).

\section{MARC Finite-Element Analysis}

Nodal temperatures from the heat-transfer analysis (via the SNIP translator) are imposed on a model to predict the elasticplastic thermal stress response of the structure using the Von Mesis yield criteria. Since thermal strains are expected to be more significant than mechanical strains, only thermal strains are accounted for in this study. Four tensile stress strain curves, each at a different temperature, are input for each of the three materials considered. These curves are used by MARC to characterize the stress-strain (work-hardening) behaviors of the materials at any given temperature in an analysis. Because of the iterative nature of a nonlinear analysis, thermal loads must be imposed in an incremental fashion to ensure solution convergence. Predicted strains from the last increment (steady state) in the solution are plotted in a post tape for evaluation in PATRAN.

\section{Boundary Conditions}

\section{Aerothermodynamic Heat Flux}

Each configuration is subjected to the same external heat flux environment. The heat flux imposed on each configuration is shown in figure 5 as a function of position and includes the simulated shock interference heating effect described by Glass et al. (1989) and Holden et al. (1988). This heat load, which is very intense $\left(\sim 50000 \mathrm{Btu} / \mathrm{ft}^{2} / \mathrm{sec}\right)$, exists over a narrow width $(\sim 1 / 20$ th $)$ of the leading-edge diameter. Because of the uncertainty in the actual shock interference heat flux, the values are used on each model even though their diameters are different.

\section{Coolant Correlations}

The emphasis of this study is to demonstrate the capability of actively cooled structures to survive in a hostile environment with an extremely high, localized heat flux. Two impingement cooling schemes and a convection cooling scheme enhanced 
by curvature are considered. Since very little information is available for impingement into a semicylinder at high Reynolds numbers, existing correlations must be extrapolated by two or three orders of magnitude in Reynolds number and the resulting heat-transfer coefficients can differ substantially from one correlation to another. A Nusselt/Reynolds number plot of two stagnation point correlations is shown in figure 6. Each correlation is rewritten so that the characteristic dimension is based on the hydraulic diameter of an equivalent slot height. The Metzger, Yamshita, and Jenkins (1969) correlation, which yields very high Nusselt numbers, and the Gardon and Akfirat (1966) correlation are used in this analysis. The Gardon correlation is obviously more conservative than the Metzger correlation at these Reynolds numbers.

Modeling the coolant path for configuration 1 is divided into three parts-the central channel, the impingement region, and the pin fin region. Separate heat-transfer correlations for each region are used. These correlations for configuration 1 are as follows:

\section{Channel (Hendricks 1979):}

$$
N u=0.025 \operatorname{Re}^{0.8} \operatorname{Pr}^{0.4} T_{r}^{n} L^{*}
$$

where

$$
\begin{gathered}
T_{r}=T_{w} / T_{b} \\
L^{*}=1.0+0.3(1 / d)^{-0.7} \\
n=-0.5
\end{gathered}
$$

\section{Impingement (Metzger, modified):}

Stagnation point-

$$
S t_{\max }=0.28 R e^{-0.3} T_{r}^{n}
$$

Distribution from stagnation point-

$$
S t=0.21 R e^{-0.3}(x / b)^{-0.52} T_{r}^{n}
$$

Pin Fin (Van Fossen 1981):

$$
N u=0.153 R e^{0.685} T_{r}^{n}
$$

All correlations are modified by the coolant to wall temperature ratio $T_{r}^{n}$ to account for large temperature differences between the fluid and the surface of the structure.

Similar coolant correlations are used in the fluid circuit analysis of configuration 2 as discussed previously. Since most of these correlations are extrapolated beyond the Reynolds number range where they were developed, an alternate impingement correlation is also used in the analysis of configurations 1 and 2 :
Impingement (Gardon):

$$
N u=1.045 R e^{0.58}(z / 2 b)^{-0.62} T_{r}^{n}
$$

The heat-transfer correlation for configuration 3 is-

Curvature (Hendricks 1963):

$$
N u=0.025 K(\theta) \operatorname{Re}^{0.8} \operatorname{Pr}^{0.4} T_{r}^{n} L^{*}
$$

where $K(\theta)$ is an augmentation factor which is a function of the channel curvature.

\section{Structural Constraints}

Structural constraints are placed on each of the three models to minimize resultant mechanical stresses in the analysis and to emphasize the thermal response. Configuration 1 is fixed to lie along its cut plane of symmetry as seen in figure 7(a). In addition, the aft end is fixed to lie in the plane perpendicular to the coolant flow as shown. Configurations 2 and 3 (fig. 7(b)) are constrained in a similar fashion at the aft end as configuration 1.

\section{Results and Discussion}

The results of these analyses are presented for each configuration and consist of characteristic temperature distributions and the resulting equivalent plastic strain due to thermal gradients. In addition, some parametric results are presented to demonstrate the effect of material characteristics and the uncertainty in the impingement-coolant Nusselt number.

\section{Impingement/Pin Fin Model}

The temperature distributions for this model are shown in figure 8 for the materials considered and the heat flux profile of figure 5. Since a large heat flux spike (fig. 5) occurs below the geometric stagnation point of the leading edge, the maximum wall temperature also occurs at the same location. This is in contrast with the peak coolant film coefficient which occurs at the stagnation point.

The thermal analyses show that the steady-state temperatures are within acceptable limits for the tungsten and the Narloy-Z copper when the Metzger impingement correlation is used. The peak temperature for tungsten is $2270{ }^{\circ} \mathrm{F}$ while the peak temperature for the copper model is $725^{\circ} \mathrm{F}$. However, the thermal analysis of the TD nickel model (not shown) indicates peak temperatures higher than its melting point. Obviously, the high thermal conductivities of tungsten and copper coupled with the high film coefficient of the Metzger correlation can maintain reasonable component temperatures.

The equivalent plastic strains in the strut are shown in figure 9. The Narloy- $Z$ model analyses predict equivalent 
plastic strains of the order of 0.07 percent while the tungsten model shows a peak level of about 0.2 percent. These equivalent plastic strains occur in a very localized region where the peak heat flux occurs.

\section{Impingement/Convection Model}

The leading-edge temperature distribution for this model is shown in figure 10 for the three materials considered and the Metzger impingement correlation. The high film coefficient from the Metzger correlation results in acceptable wall temperatures even for the low thermal conductivity TD nickel case. As might be expected, the temperatures and temperature gradients are inversely proportional to the material thermal conductivity. Narloy- $Z$ has the lowest temperature of $270{ }^{\circ} \mathrm{F}$ peak and the lowest temperature gradient; TD nickel has the highest temperature $\left(1850{ }^{\circ} \mathrm{F}\right)$ and thermal gradients. The tungsten model has a peak temperature of $780^{\circ} \mathrm{F}$.

The predicted peak equivalent plastic strains resulting from the thermal gradients in these materials and this model are shown in figure 11 . The results are relatively low for both the tungsten and Narloy- $Z$ cases at 0.2 - and 0.4 -percent strain, respectively. However, TD nickel shows a peak strain over 1 percent. This is due to the more severe thermal gradient for the TD nickel case.

A temperature distribution and equivalent plastic strains for - this model are shown in figure 12 for the Gardon impingement correlation and tungsten material. The maximum wall temperature is higher $\left(2410^{\circ} \mathrm{F}\right)$ than it was in the previous case because of the lower film coefficient predicted by the Gardon correlation. The equivalent plastic strain predicted for this case is also significantly greater ( 3 times) than that predicted when using the high film coefficient. This demonstrates the need to define accurately the internal film coefficient in this region.

The maximum model wall temperature for each material type and the two impingement correlations are shown in figure 13. One conclusion to be drawn from this figure is that the importance of high material thermal conductivities is reduced if high-impingement film coefficients (as predicted by the Metzger correlation) are achievable. However, if the Gardon correlation predictions are more nearly correct, then material thermal conductivity becomes very important and the thermal conductivity levels represented by Narloy-Z (or better, such as a graphite/copper metal matrix composite) are required for good overall performance. Another conclusion implicit in these results is that thermal gradients are reduced by high material thermal conductivity which will, in turn, moderate the thermally induced stresses.

\section{Convection-Cooled Model}

Wall temperatures are higher for this cooling scheme when compared to the concepts just discussed. As before, the TD nickel analysis predicted leading-edge melting in the region of the large heat flux spike. Figures 14(a) and (b) show the wall temperature distributions for tungsten and Narloy- $Z$, respectively. These temperatures are 2730 and $720^{\circ} \mathrm{F}$, respectively, and are within typical operating limits for these materials.

The coolant-side film coefficient for this configuration is enhanced by the curvature effects of the passage. Only inner and outer radii enhancement data are available for some general radii of curvature. Three-dimensional effects within the passage, which are important at these heat flux levels and should be considered in the analyses, are not available.

The results for tungsten show a large thermal gradient in the region of high heat flux. Despite this high thermal gradient, the peak equivalent plastic strain for this case is only 0.7 percent (fig. 15(a)). This is due to the high yield stress for tungsten. In addition, Narloy- $Z$ has a relatively low peak equivalent plastic strain of 0.4 percent (fig. 15(b)) reflecting the lower thermal gradient.

\section{Concluding Remarks}

Detailed thermal/structural analyses have been performed on several actively cooled concepts that might be applied as leading-edge configurations in a hypersonic flow field where large localized heat flux may occur. These concepts rely on enhanced internal cooling configurations using hydrogen as a coolant and highly conductive materials to spread the incident heat flux over a large area. There is, however, a significant level of uncertainty in the internal film coefficients for the Reynolds numbers considered for this application. Further study in this area, including a study of three-dimensional fluid dynamics effects, is desirable.

The combination of high internal film coefficients, which may be attained with the impingement concept or other enhanced convection cooling concept, and the high thermal conductivity of a copper alloy or tungsten keeps the maximum wall temperature within acceptable limits for most configurations. However, the large thermal gradients result in a noticeable amount of equivalent plastic strain (and deformation) in the leading-edge region. With this in mind, it is necessary to further investigate the behavior of these structures by incorporating mechanical, cyclic, and timedependent effects. With plastic strain occurring at high temperatures, a number of other phenomena can take place such as creep ratching and/or creep buckling where small amounts of plastic strain can accumulate over a period of time or a number of cycles and could ultimately result in structural failure. These mechanisms, as well as life prediction, need to be considered in more sophisticated analyses.

Tungsten appears to be the material of choice for each of these cases with its high-temperature capability and high yield stress. Obviously, its affinity for oxygen requires some type of barrier coating for its hot surface exposed to air. In addition, the potential for plastic deformation requires further analyses of time-dependent characteristics as mentioned previously. 


\section{References}

Aerospace Structural Metals Handbook, Battelle Columbus Laboratories, Columbus, OH, 1967.

Gardon, R., and Akfirat, J.C., "Heat Transfer Characteristics of Impinging Two-Dimensional Air Jets, " Journal of Heat Transfer, Vol. 88, No. 1, Feb. 1966, pp. 101-108.

Glass, C.E., Wieting, A.R., and Holden, M.S., "Effect of Leading Edge Sweep on Shock-Shock Interference at Mach 8, " AIAA Paper 89-0271, Jan. 1989.

Hendricks, R.C., and Simon, F.F., "Heat Transfer to Hydrogen Flowing in a Curved Tube," Multi-Phase Flow Symposium, Proceedings ASME Winter Annual Meeting, Philadelphia, PA, Nov. 17-22, 1963, edited by N.J. Lipstein, ASME, New York, 1963, pp. 90-93.

Hendricks, R.C., Yeroshenko, V.M., Yaskin, L.A., and Starostin, A.D., "Bulk Expansion Factors and Density Fluctuations in Heat and Mass Transfer," Presented at the International Congress of Refrigeration, 15th, Venezia, Sept. 23-29, 1979, Vol. 2, paper B1-119.

Holden, M.S., Wieting, A.R., Moselle, J.R., and Glass, C.E., "Studies of Aerothermal Loads Generated in Regions Of Shock/Shock Interaction In Hypersonic Flow," AIAA Paper 88-0477, Jan. 1988.
Killackey, J.J., Katinszky, E.A., Tepper, S., Vuigner, A.A., Wright, C.C., and Stockwell, G.G., "Thermal-Structural Design Study of an AirframeIntegrated Scramjet. Final Report, June 1975-Dec. 1979," NASA CR-159039, 1980.

McCarty, R.D., "Hydrogen Technology Survey-Thermophysical Properties," NASA SP-3089, 1975.

Metzger, D.E., Yamshita, T., and Jenkins, C.W., "Impingement Cooling of Concave Surfaces With Lines of Circular Air Jets," Journal of Engineering for Power, Vol. 91, No. 3, July 1969, pp. 149-158.

Touloukian, Y.S., ed., Thermophysical Properties of Matter, Vol. I, Thermal Conductivity: Metallic Elements and Alloys, Plenum Data Corp., New York, 1970.

Van Fossen, G.J., "Heat Transfer Coefficients for Staggered Arrays of Short Pin Fins,” NASA TM-81596, 1981.

Winegar, S.R., "SINDA-NASTRAN Interfacing Program. Theoretical Description and Users Manual," NASA TM-100158, 1987. 

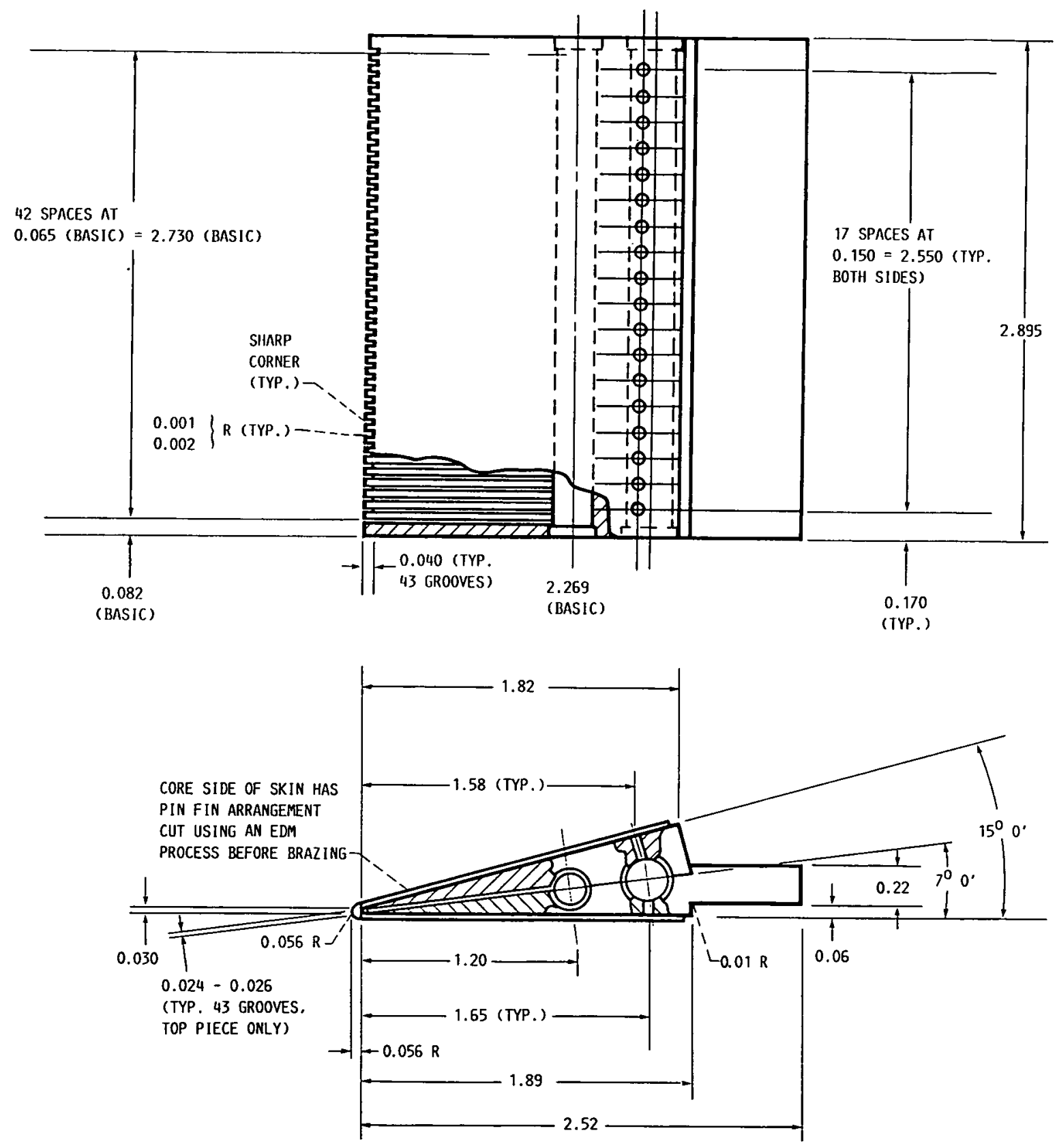

Figure 1.-Impingement/pin fin-cooled model designed as a strut support in a hypersonic flow field. (All dimensions are in inches unless indicated otherwise.) 


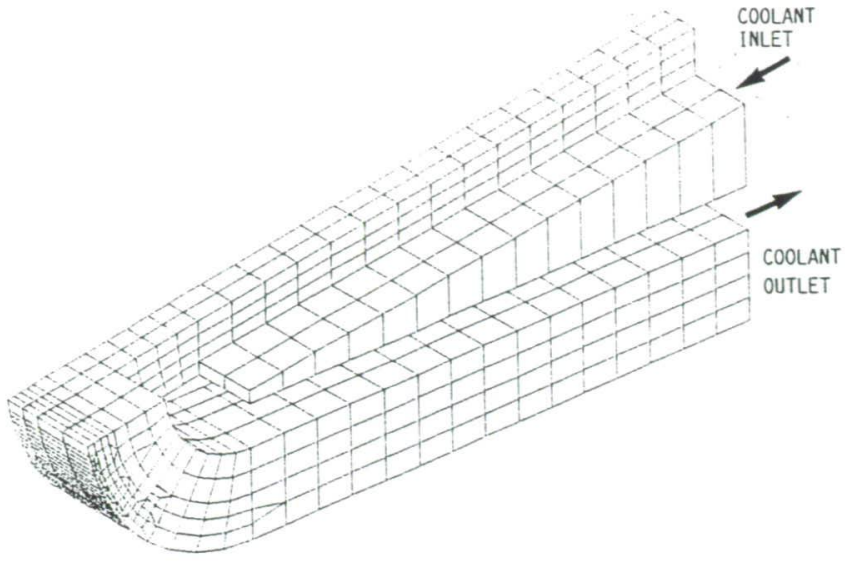

Figure 2.-Finite-element model of impingement/pin fin-cooled strut.

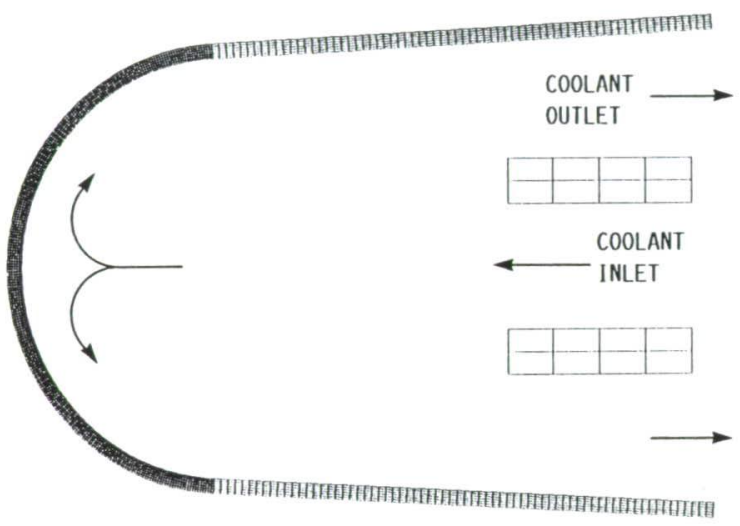

Figure 3.-Finite-element model of impingement/convection-cooled leadingedge model.

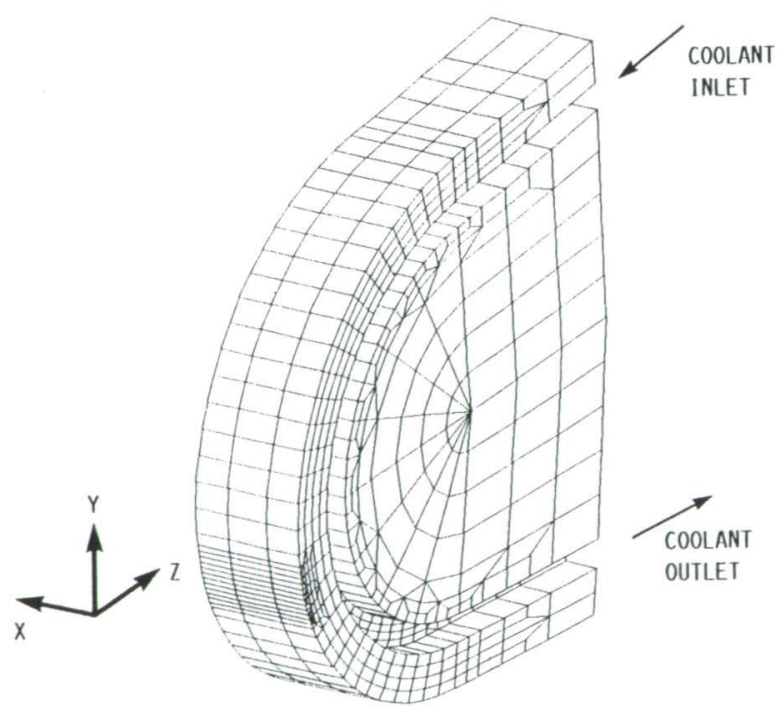

Figure 4.-Finite-element model of convection-cooled leading-edge model.

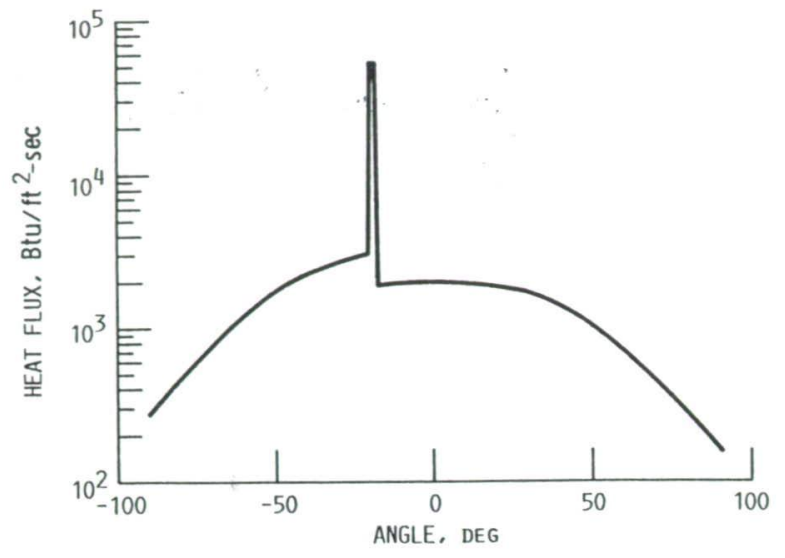

Figure 5.-Shock interference heat flux boundary condition near leading-edge stagnation point.

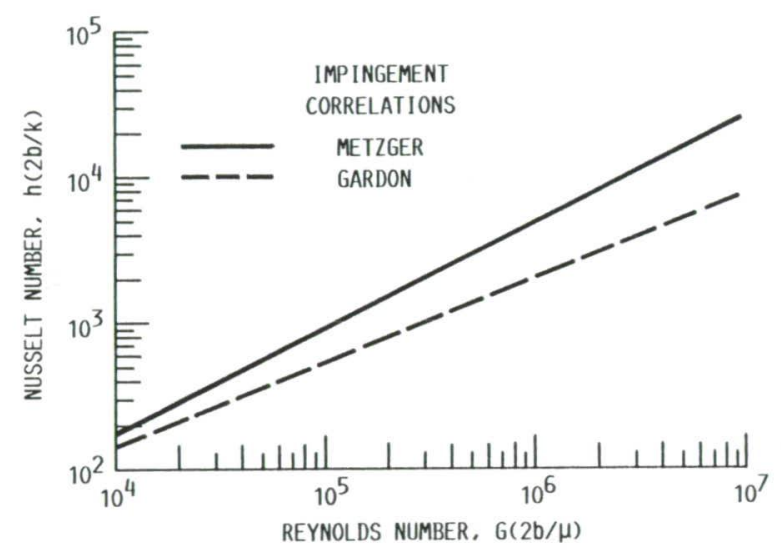

Figure 6.-Comparison of leading-edge stagnation point impingement cooling correlations.

(a)

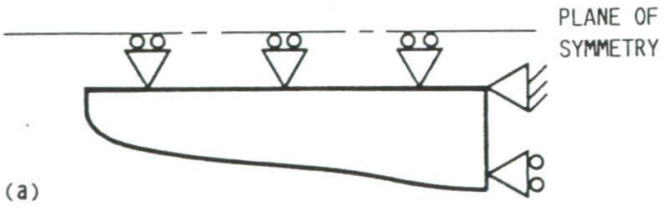

(b)
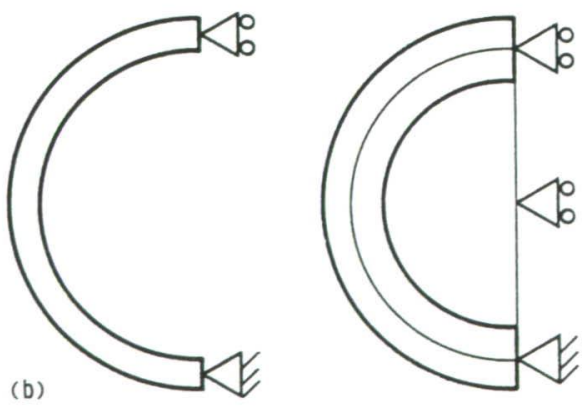

(a) Impingement/pin fin-cooled model.

(b) Impingement/convection-cooled and convection-cooled models.

Figure 7.-Structural constraints. 


\section{ORIGINAL PAGE COLOR PHOTOGRAPH}
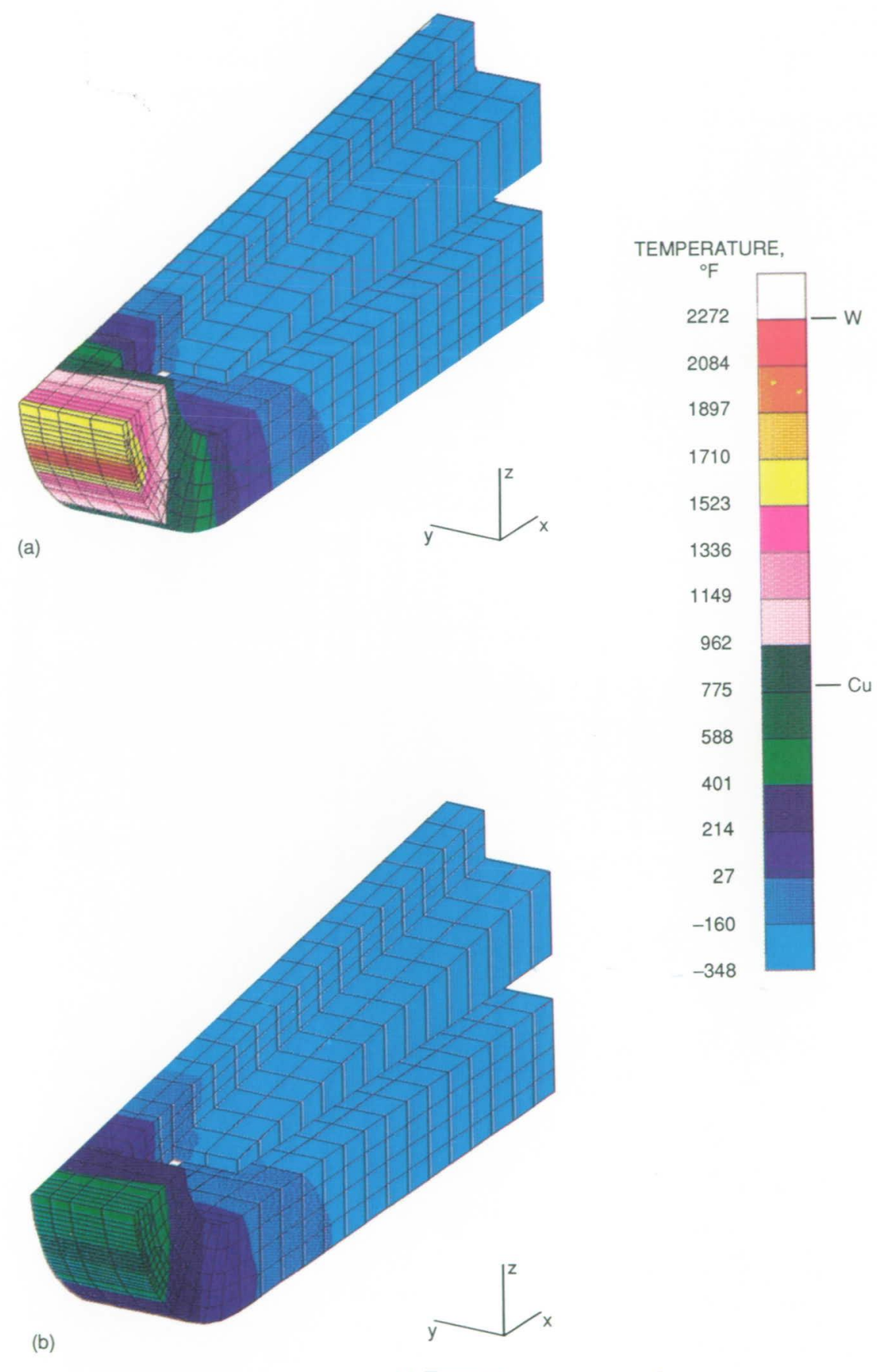

(a) Tungsten

(b) Narloy-Z copper

Figure 8.-Comparison of wall temperatures for three material types in impingement/pin fin-cooled model using Metzger impingement correlation. 


\section{$\because$ \\ ORIGINAL PAGE COLOR PHOTOGRAPH}

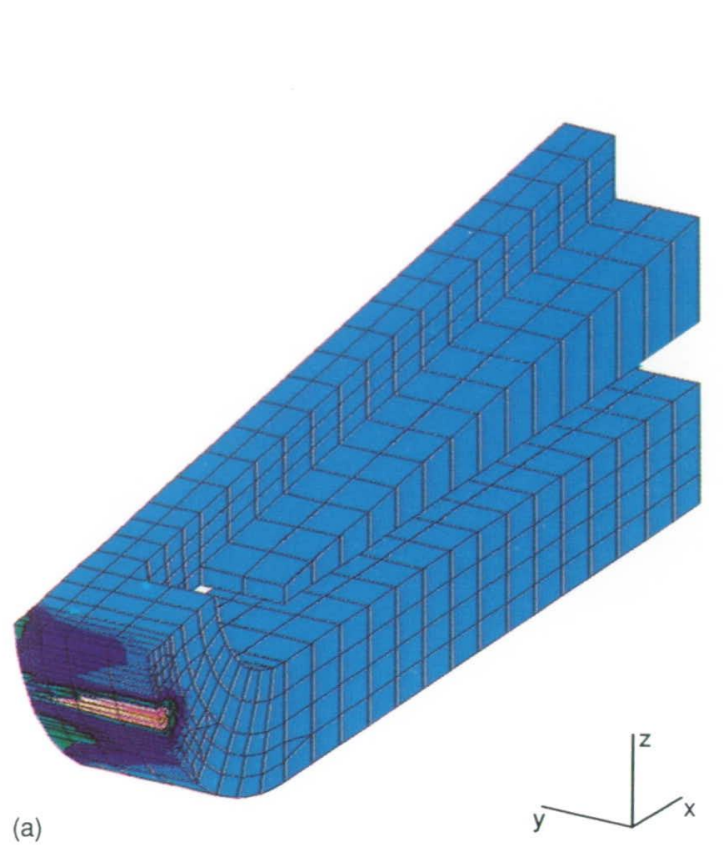

(a)
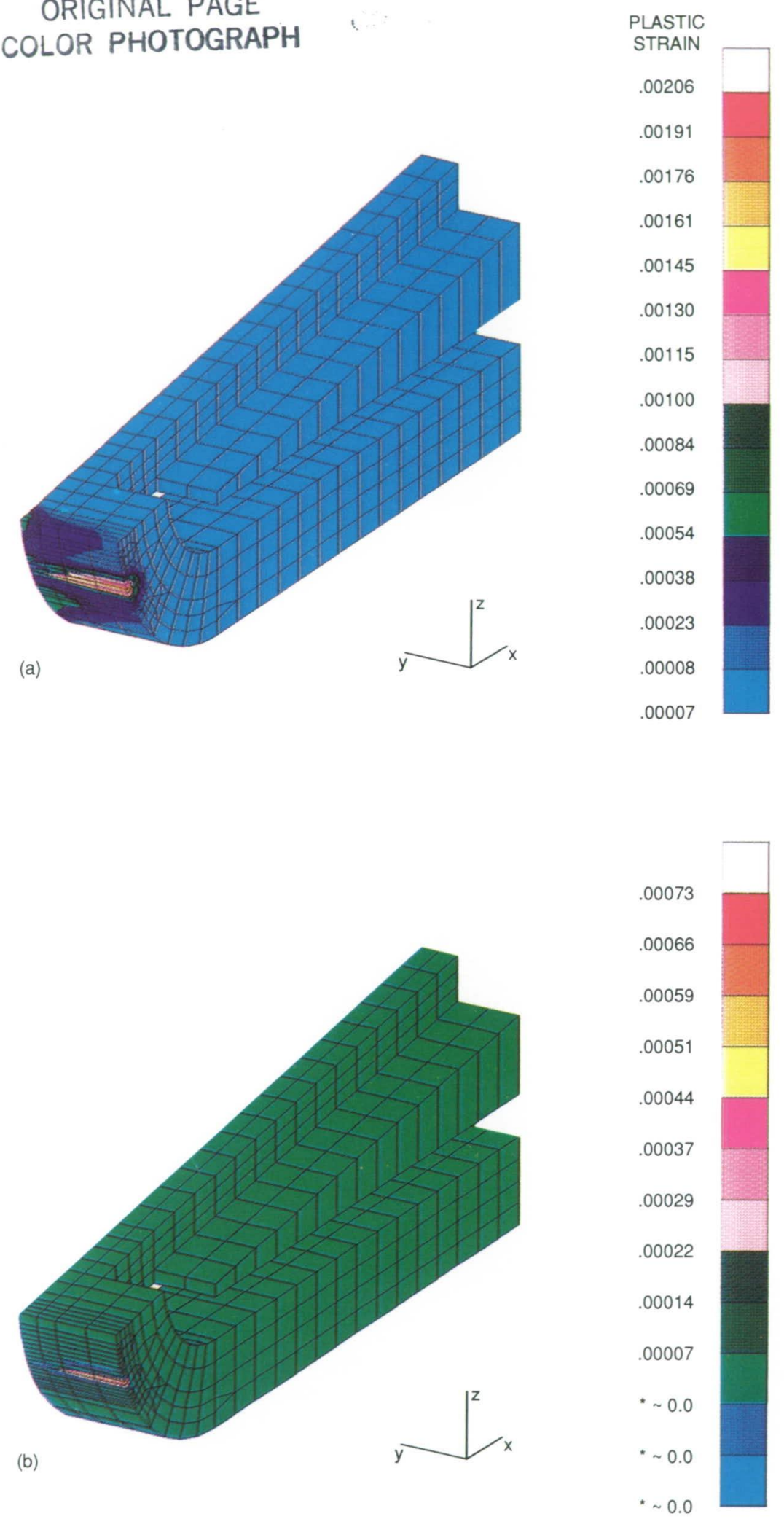

(a) Tungsten.

(b) Narloy-Z copper.

Figure 9.-Comparison of equivalent plastic strain in impingement/pin fin-cooled model for three material types. 


\section{i \\ ORIGINAL PAGË. \\ COLOR PHOTOGRAPH}

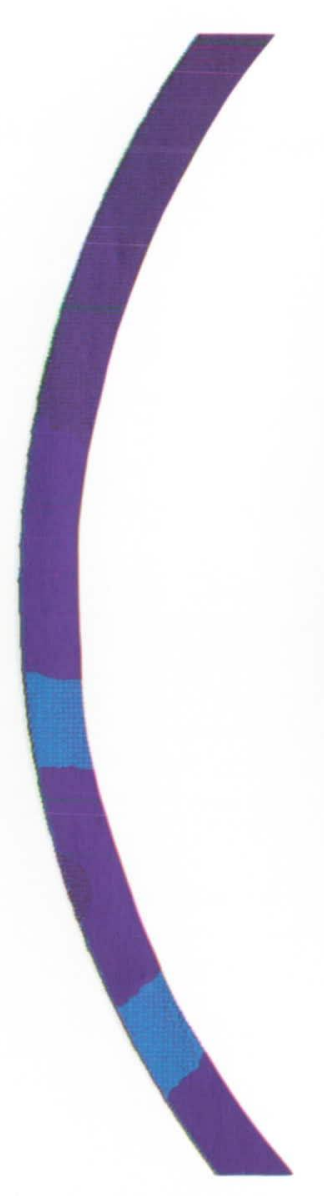

NARLOY-Z COPPER

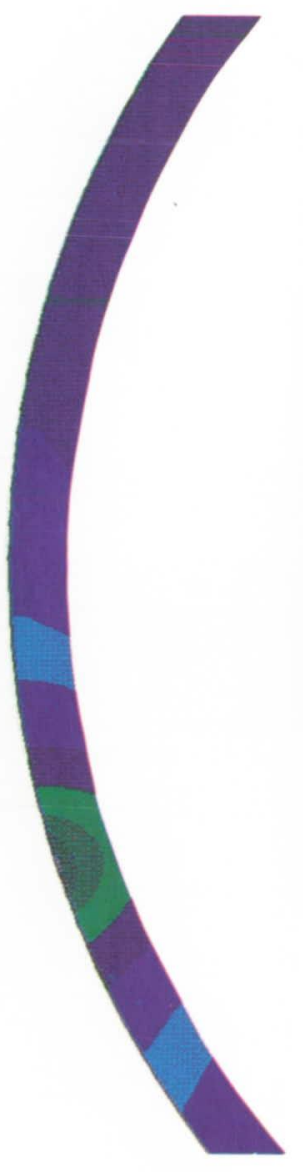

TUNGSTEN

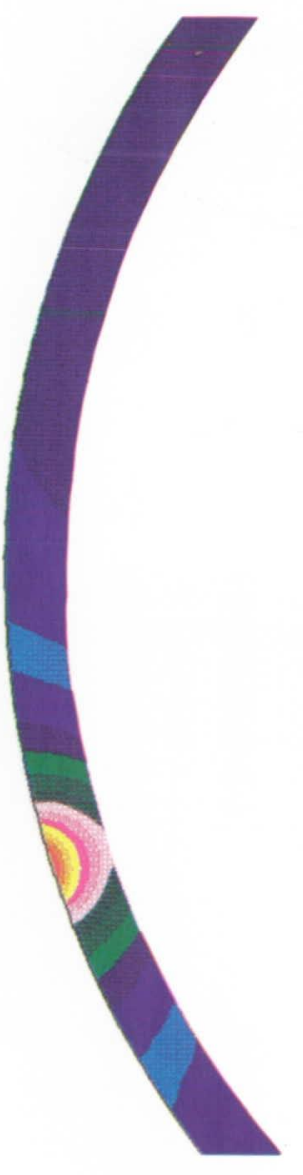

TD NICKEL

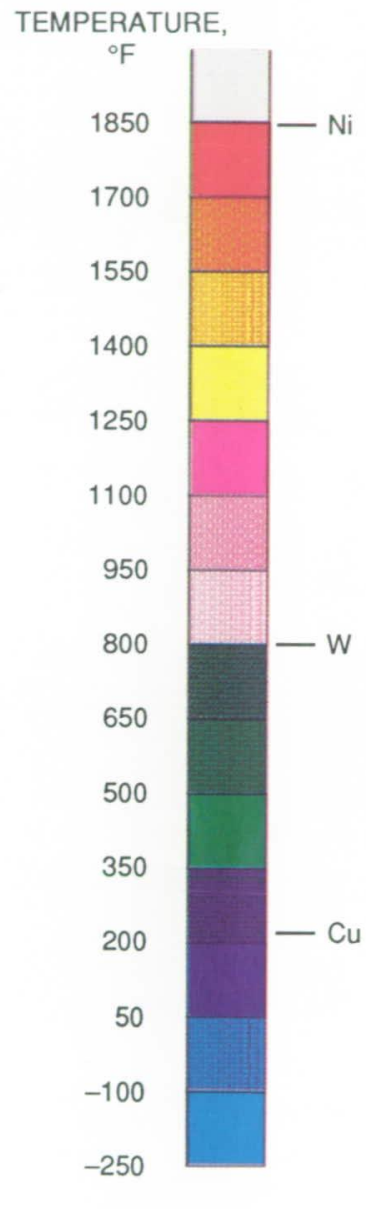

Figure 10.-Comparison of wall temperatures for three material types in impingement/convection-cooled model using Metzger impingement correlation. 


\section{ORIGINAL PAGE \\ COLOR PHOTOGRAPH}
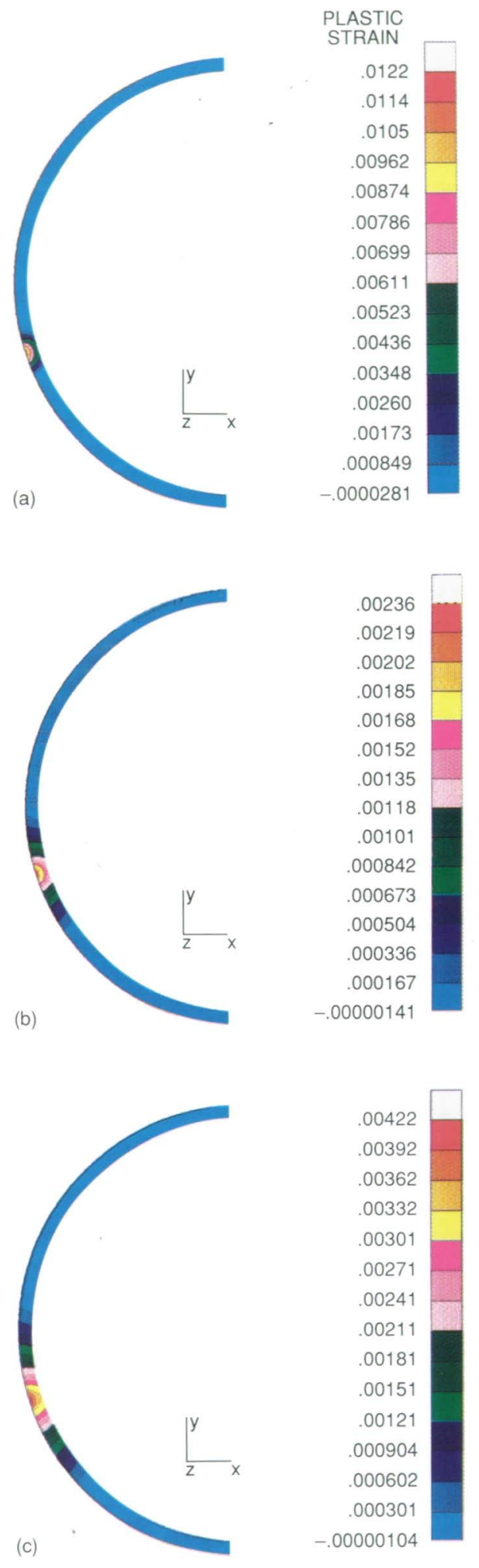

(a) TD nickel.

(b) Tungsten.

(c) Narloy-Z copper.

Figure 11.-Equivalent plastic strain distribution in impingement/convectioncooled leading-edge model using Metzger correlation.

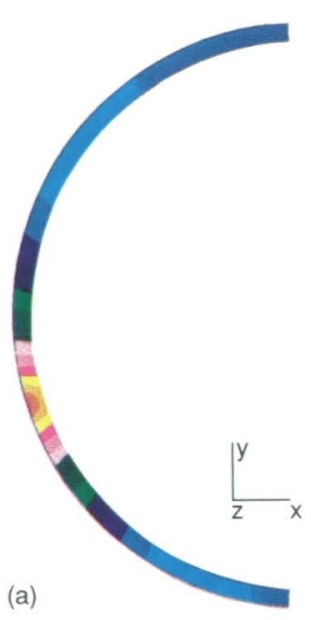

TEMPERATURE,
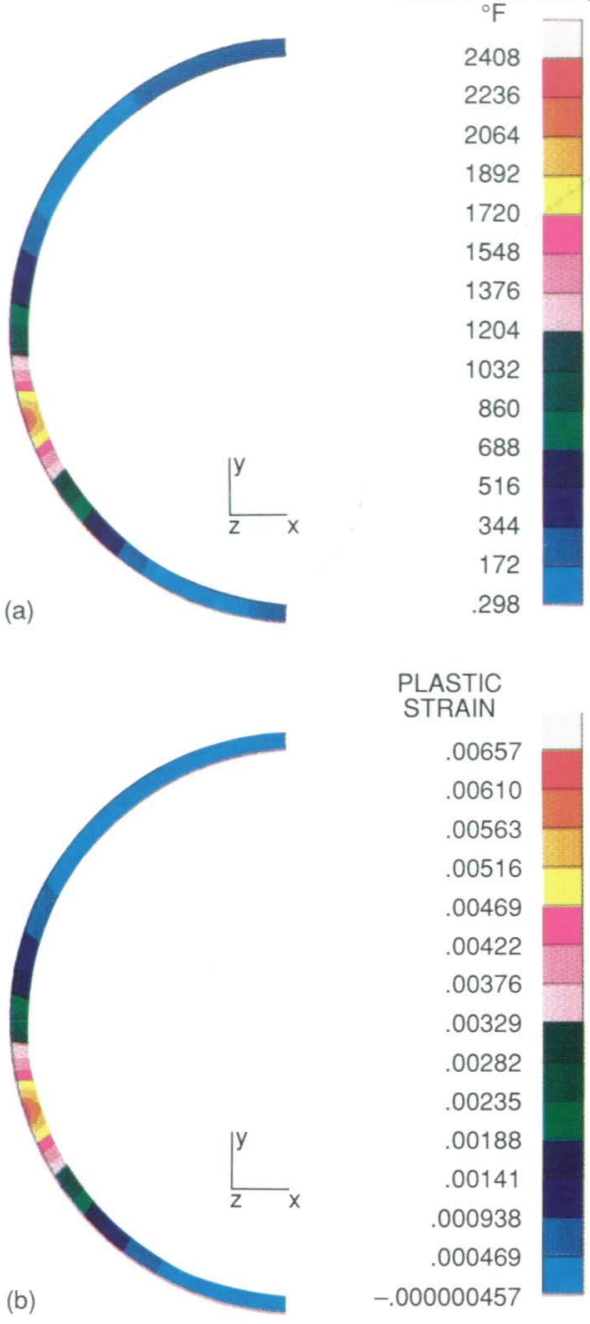

(a) Temperature distribution

(b) Equivalent plastic strain

Figure 12.-Wall temperature and resulting plastic strain distribution in tungsten leading-edge model when Gardon impingement correlation is used.

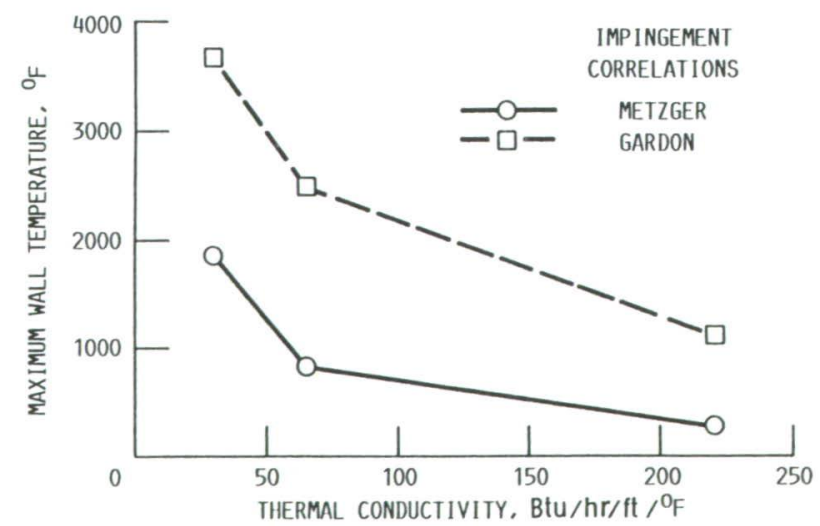

Figure 13.-Maximum wall temperature as function of material thermal conductivity. 


\section{ORIGINAL PAGE \\ COLOR PHOTOGRAPH}
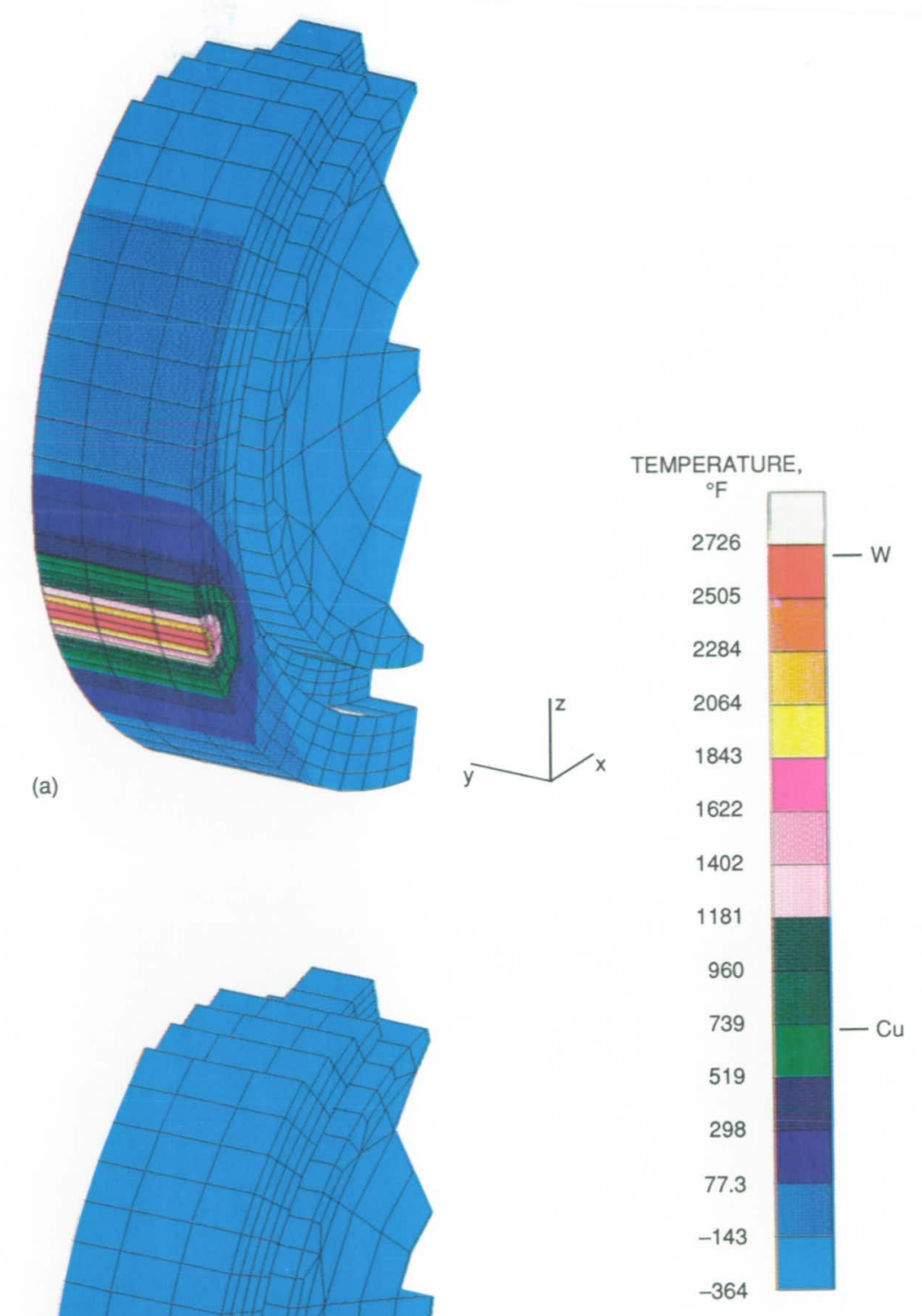

(b)
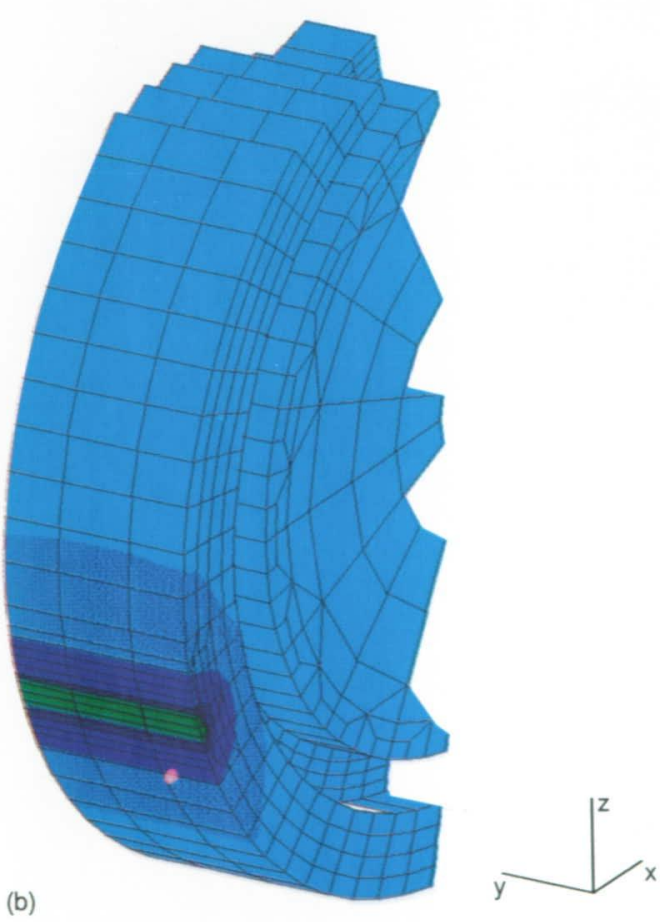

(a) Tungsten.

(b) Narloy-Z copper.

Figure 14.-Wall temperature distribution in convection-cooled leading-edge model. 
ORIGINAL PAGE

COLOR PHOTOGRAPH
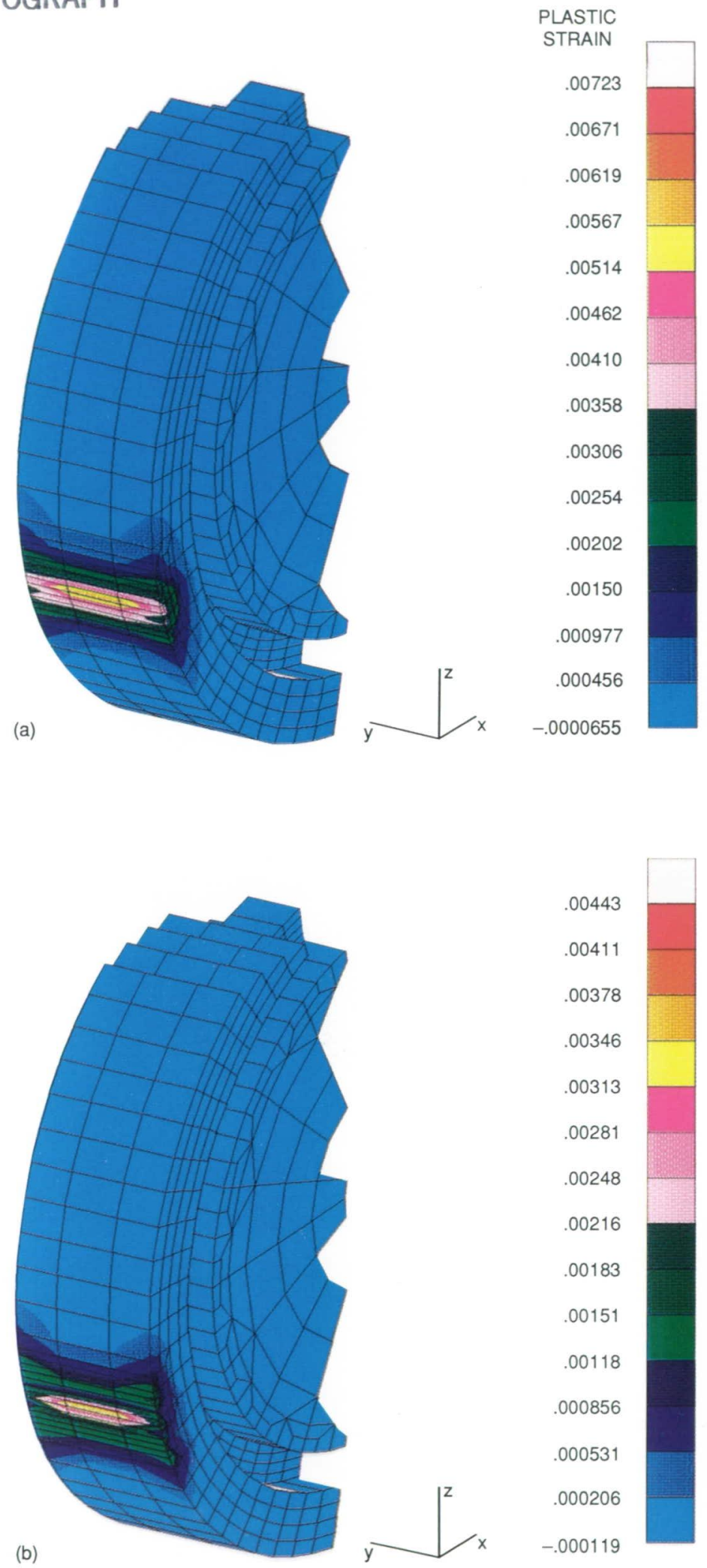

(a) Tungsten.

(b) Narloy-Z copper.

Figure 15.-Equivalent plastic strain distribution in convection-cooled leading-edge model. 


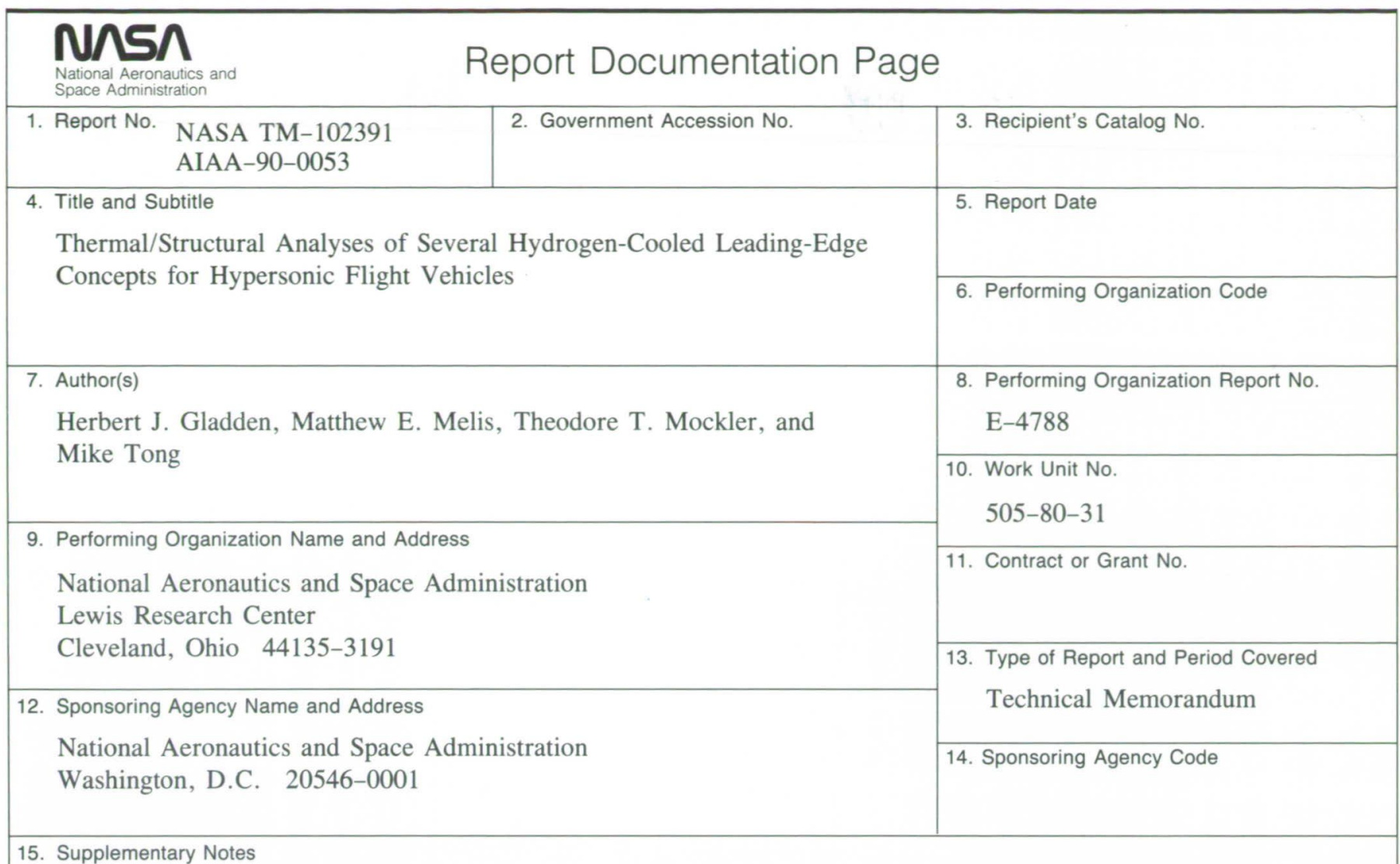

Prepared for the 28th Aerospace Sciences Meeting sponsored by the American Institute of Aeronautics and Astronautics, Reno, Nevada, January 8-11, 1990. Herbert J. Gladden, Matthew E. Melis, and Theodore T. Mockler, NASA Lewis Research Center; Mike Tong, Sverdrup Technology, Inc., NASA Lewis Research Center Group, Cleveland, Ohio 44135 .

16. Abstract

The aerodynamic heating at high flight Mach numbers, when shock interference heating is included, can be extremely high an can exceed the capability of most conventional metallic and potential ceramic materials available. Numerical analyses of the heat transfer and thermal stresses are performed on three actively cooled leading-edge geometries (models) made of three different materials to address the issue of survivability in a hostile environment. These analyses show a mixture of results from one configuration to the next. Results for each configuration are presented and discussed. Combinations of enhanced internal film coefficients and high material thermal conductivity of copper and tungsten are predicted to maintain the maximum wall temperature for each concept within acceptable operating limits. The exception is the TD nickel material which is predicted to melt for most cases. The wide range of internal impingement film coefficients (based on correlations) for these conditions can lead to a significant uncertainty in expected leading-edge wall temperatures. The equivalent plastic strain, inherent in each configuration which results from the high thermal gradients, indicates a need for further cyclic analysis to determine component life.

\begin{tabular}{|c|c|c|c|c|}
\hline $\begin{array}{l}\text { 17. Key Words (Suggested by Author(s)) } \\
\text { Heat transfer } \\
\text { Structural analysis }\end{array}$ & & $\begin{array}{l}\text { 18. Distribu } \\
\text { Unc } \\
\text { Sub }\end{array}$ & $\begin{array}{l}\text { nent } \\
\text { - Unlimited } \\
\text { gory } 34\end{array}$ & \\
\hline $\begin{array}{l}\text { 19. Security Classif. (of this report) } \\
\text { Unclassified }\end{array}$ & $\begin{array}{l}\text { 20. Security Classif. (of } \\
\text { Uncla }\end{array}$ & $\begin{array}{l}f \text { this page) } \\
\text { assified }\end{array}$ & $\begin{array}{c}\text { 21. No of pages } \\
15\end{array}$ & $\begin{array}{r}\text { 22. } \text { Price }^{\star} \\
\mathrm{A} 03\end{array}$ \\
\hline
\end{tabular}


National Aeronautics and Space Administration

Lewis Research Center

Cleveland, Ohio 44135

Orficial Business

Penalty tor Private Use $\mathbf{5 3 0 0}$

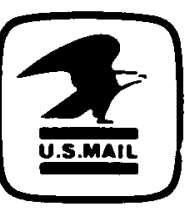

Posiage and Fees Pad

National Aerendutics and

Space Adnunistratiun

$\checkmark A S A$ 45, 


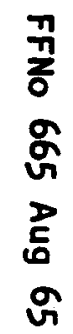

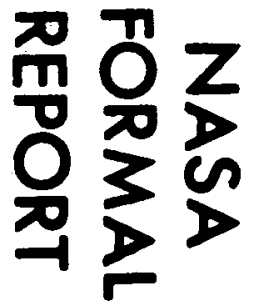

